\title{
Clinical Study of Postpartum Eclampsia
}

\author{
Dr. S. K. Rath ${ }^{1}$, Dr. Swati Agrawal ${ }^{2}$ \\ Professor \& HOD, +Senior Resident PDVVPF's Medical College, Vilad Ghat Ahmednagar 414111, Maharashtra, India
}

\begin{abstract}
Eclampsia continues to be one of the leading causes of Maternal morbidity and mortality in developing countries. It is true that with the outreach of Governments and Non Government agencies, more women are able to access antenatal care. This has increased the scope of early detection of cases of hypertension during pregnancy and thereby preventing development of eclampsia. However, with the degree of watchfulness abating in postnatal period, risk of development of postpartum eclampsia, particularly late onset ones looms large. We analyzed the data pertaining to eclampsia cases encountered in our hospital for two years and found that there is a relative rise in the incidence of postpartum eclampsia. Treatment protocol remains the same but the outcome is better with less chances of complicating other systems when compared with antenatal and intranatal variants.
\end{abstract}

Keywords: Eclampsia, Maternal morbidity, Maternal mortality, Postpartum, Hypertension

\section{Introduction}

Eclampsia has been described as enigmatic, unpredictable and dramatic complication of pregnancy $(1,2)$. Enigmatic because of it's ill understood etiology. Unpredictable because it is sudden and may not be associated with classical prodromal symptoms. Dramatic because of the serious turn of events occurring in a seemingly normal individual. Eclamptic seizures is a potentially tragic complication of hypertensive disorders of pregnancies, contributing significantly to maternal morbidity and mortality in developing countries (3). Identification of these hypertensive disorder in pregnancy remains the cornerstone of preventing seizures.

This realization has led the state and non state agencies to direct their energy and resources to make antenatal examination and hospital delivery easily available to mass.

With improvement in antenatal care and intervention, reduction in cases of eclampsia is expected. When eclampsia occurs , unquestionable popularity of magnesium sulphate as the preferred therapy has been saving life (4). However, the degree vigilance following delivery not being the same, the subset of postpartum eclampsia may be a cause of concern. There have been increasing reports of late onset postpartum eclampsia beyond traditional 48 hours $(5,6)$. We undertook an analysis of eclampsia cases treated in our institution with particular focus on the subset of postpartum eclampsia.

\section{Material and Method}

Retrospective study of all eclampsia cases treated between Jan 2014 to Dec 2015 was carried out. Following an earlier study on effectiveness of low dose magnesium sulphate therapy in our institution (7), treatment protocol has been uniform, with a loading dose of $9 \mathrm{gm}$ and maintenance dose of $2.5 \mathrm{gm}$ four hourly with a clear option of converting to full dose protocol of Pritchard (8) in case of recurrence of seizure.

Parameters observed were as under

a) Age and Parity

b) Period of gestation

c) Pre existing preeclampsia d) Point of occurrence

e) Mode of Delivery

f) Repeat seizure

g) Drug Toxicity

h) Other systemic Complication

i) Neonatal outcome

\section{Observations}

Table 1: Case Distribution

\begin{tabular}{|c|c|c|c|c|c|c|c|}
\hline \multicolumn{2}{|c|}{ Age Distribution } & \multicolumn{2}{|c|}{$\begin{array}{c}\text { Parity } \\
\text { Distribution }\end{array}$} & \multicolumn{2}{l|}{ Time Distribution } & $\begin{array}{c}\text { Total } \\
\text { Cases }\end{array}$ \\
\hline$<20$ & $20-30$ & $>30$ & Primi & Multi & Antenatal & Postnatal & \\
\hline 3 & 9 & 1 & 9 & 4 & 8 & 5 & 13 \\
\hline
\end{tabular}

It was found that we had 13 cases of eclampsia during the observed period. Overall incidence was $1.6 \%$ of total deliveries. Maximum number of cases were young primigravida, in the age group of twenties. Postnatal eclampsia constituted $38.4 \%$ of total number of eclampsia cases. Time of occurrence of postnatal eclampsia ranged between 30 minutes to 12 days. 3 cases were within classical 48 hours and 1 each on the 7 th day and $12^{\text {th }}$ day after delivery

Table 2: Preeclampsia, Recurrence, Complications and Toxicity

\begin{tabular}{|c|c|c|}
\hline & $\begin{array}{c}\text { Antenatal } \\
\text { Eclampsia } \\
(\mathrm{n}: 8)\end{array}$ & $\begin{array}{c}\text { Postnatal } \\
\text { Eclampsia } \\
(\mathrm{n}: 5)\end{array}$ \\
\hline Preeclampsia & 8 & 3 \\
\hline Recurrence of Seizures & 2 & - \\
\hline Drug Toxicity & 1 & - \\
\hline HELLP & 1 & 1 \\
\hline Oliguria & 1 & - \\
\hline Abruption & 1 & - \\
\hline DIC & 1 & - \\
\hline
\end{tabular}

What stands out in the observations of Table 2 is that in the postnatal sub group a preexisting preeclampsia was not present in some of the cases and other systemic complications were rare. Only case of magnesium sulphate toxicity we had was in the form of respiratory depression which was reversed with calcium gluconate. Cause identified was a human error where the dose had not been 


\section{International Journal of Science and Research (IJSR) \\ ISSN (Online): 2319-7064 \\ Index Copernicus Value (2013): 6.14 | Impact Factor (2014): 5.611}

discontinued at the appropriate time. There were repeat seizure in 2 cases while on low dose protocol. They were managed by administration of an intravenous bolus dose of 2 gm and conversion to full dose protocol.
Mode of delivery and neonatal outcome for all the cases are summarized in table 3 .

Table 3: Delivery \& Neonate

\begin{tabular}{|cc|cc|cc|c|}
\hline \multicolumn{2}{|c|}{ Mode of Delivery } & \multicolumn{2}{|c|}{ Period of Gestation } & \multicolumn{2}{|c|}{ Neonatal outcome } & Remarks \\
\hline Vaginal & LSCS & Term & Preterm & Morbidity* & Mortality & \\
\hline 10 & 3 & 7 & 6 & 3 & 1 & *Asphyxia Prematurity RDS \\
\hline
\end{tabular}

\section{Discussion}

Two derangements have been proposed to underlie the development of focal cerebral edema which leads to eclamptic fits viz: vasospasm and forced dilation (9). Either of these proposed vasogenic events could provide the anatomic substrate for widespread CNS insults with resultant premonitory symptoms and convulsions that characterize eclampsia. Whereas etiology of eclampsia might not be clear it's recognition is obvious and alarming. Onset is after 20 weeks of gestation. Most cases occur close to term. Postpartum eclampsia traditionally described during first 48 hours of delivery is characterized by volatile hypertension, proteinuria, edema, and seizures. Convulsions commonly occur after the onset of one or more isolated prodromal symptoms (headache, visual change, epigastric pain, facial or hand edema, or sudden weight gain), or they can accompany the emergence of overt preeclampsia in women receiving regular obstetric care. Yet there may be absolutely no premonitory warning symptoms or documented blood pressure increase until just before convulsions, as was the instance three of our case. In fact, Sibai observed that $19 \%$ to $32 \%$ of eclamptic patients analyzed in a series were without antecedent indicators of hypertensive pregnancy complications. (10)

Eclampsia continues to complicate pregnancy in our country. Incidence from 0.8 to $3.2 \%$ of hospital delivery have been reported (11) which are very high compared to developed countries where the figures are $0.05 \%$. Most authorities report that 18 to $25 \%$ of seizures occur in the postpartum periods, (12) whereas in our series $38.4 \%$ were of postpartum sub group. It is seen that access to antenatal care has improved over time, where in overt cases of preeclampsia are identified and treated. Since some cases of eclampsia are preceded by hypertension only very briefly, it is possible to miss them. This could be the reason for relative rise in postpartum eclampsia. Vigilance and watchfulness in postpartum period is of extreme importance.

We have used a low dose protocol of magnesium sulphate for treatment of eclampsia following the results of an earlier publication from our institution. There have been popularity of variants of a low dose protocol particularly in South Asia. (13) because of low body mass index of the population. Risk of recurrence of seizures are reported between $6 \%$ to $8 \%$ in larger reported series (14). In our series, there was recurrence in $15 \%$ cases. With a small series as ours, incidence may not be representative. All of them were successfully managed by converting to full dose protocol. Drug toxicity is rare and can be identified by strict monitoring and adherence to protocol. Only case we encountered was in a recurrence case converted to full dose protocol, where in the schedule extended beyond twenty four hours of last seizure. Magnesium sulphate is a potent and very effective drug. Fine tuning of dose schedule and adherence to protocol are extremely important. Some workers have advocated a full dose protocol for 12 hrs instead of 24 hours following last seizure to minimize risk of toxicity. (15)

Prognosis of eclampsia cases depends on timely reaching the hospital and coexistence of any other systemic complication. In postpartum variety these complications (DIC/ HELLP/ Oliguria/ Abruption) are much less, thereby holding a better prognosis. There was no maternal mortality in our series. Immediate delivery is one of the essentials in treating eclampsia, irrespective of fetal maturity. Consequently, neonatal morbidity is primarily related to maturity at the time of delivery. We had 3 cases of significant morbidity and one mortality of neonate which was related to prematurity.

Timing of postpartum eclampsia has been a matter of discussion Though conventionally described to be occurring within 48 hours of delivery, there have been reports of late onset postpartum eclampsia after one to two weeks.( 5, 6 ). There has also been claim of such a case after 8 weeks of delivery (16). In our series there were two cases of late onset eclampsia being on 7 th and $12^{\text {th }}$ day. Cerebral oedema with ischemic foci within gray matter in the distribution of the posterior cerebral arteries were present on MRI. However, during follow up, MRI and EEG were normal in both the cases, ruling out any other intracranial lesion.

\section{References}

[1] Cunningham FG ,Macdonald etal,editors. Hypertensive disorders of Pregnancy.In : Williams Ob cstetrics. $19^{\text {th }}$ Edition. : Appleton and Lange,1993: 763-817

[2] Donaldson JO. Eclampsia. In:. Devinski O, Feldman E, Hainline B, editors. Neurological complications of pregnancy. New York: Raven Press, 1994:25-33.

[3] Arora R,Ganguli RP,Swain S,Oumachigui,Rajaram P. Determinants of maternal mortality in Eclampsia in India. Australian and Newzeland $\mathrm{J}$ of obstet and Gynecol 1994;34:537-539 republished online 2008

[4] Chien PF, Khan KS, Arnott N. Magnesium sulphate in the treatment of eclampsia and pre-eclampsia: an overview of the evidence from randomised trials. Br J Obstet Gynaecol 1996;103:1085-91.

[5] Department of Family Medicine, , Department of Family Medicine, and , Department of Neuroradiology, Medical College of Georgia, Augusta Late Postpartum Eclampsia 16 Days After Delivery: Case Report With Clinical, diologic, and Pathophysiologic Correlations.J 
Am Board Fam Med. 2000;13(1)

[6] Val E. Ginzburg, Bryan Wolff Headache and seizure on postpartum day 5: late postpartum eclampsia. CMAJ February 17, 2009 vol. 180 no. doi: 10.1503/cmaj.071446

[7] Aher GS,Gavli U.Body friendly,safe and effective regimen of Magnesium sulphate for eclampsia.International $\mathrm{J}$ of Med Research and Health Sciences 2013;2:83-86

[8] Pritchard JA. The use of magnesium sulphate in eclamptogenic toxemias.Surg Gynecol Obstet. 1955;100:131-140

[9] Lindheimer MD, Katz AI. Pathophysiology of pre-eclampsia. Annu Rev Med 1981;32:273- 89.

[10] Sibai BM. Eclampsia. VI. Maternal-perinatal outcome in 254 consecutive cases. Am J Obstet Gynecol 1990;163:1049 -55.

[11] Singh S,Behera AK. Eclampsia in Eastern India. Incidence, Demograph profile andresponse to treatment by three different regime. The Internet J of Gynecol and Obstet 2010;15:212

[12] Sibai BM. Hypertension in pregnancy. In: Gabbe SG, Niebyl JR, Simpson JL, editors. Obstetrics: normal and problem pregnancies. 3rd ed. New York: Churchill-Livingstone, 1996:935-996.

[13] Suvarna VN, Malapaka. Priya K Ballal Low dose magnesium sulphate versus Pritchard regime for the treatment of eclampsia, imminent eclampsia. International J of Obstet Gynecol 2011; 115:70-7214

[14] Jana N,Dasgupta S,Das AK. .Experience of a low dosemagnesium sulphate regimen over a decade. International J of Obstet Gynecol 2013; 122:13-17 low recurrence $6.1 \%$ mean wt 41.7

[15] Saheen A,Goel N,Sharma R. Moshin Z. maternal outcome after $12 \mathrm{hr}$ and 24 hours of magnesium sulphate therapy for eclampsia. International J of Obstet Gynecol 2016;132: 68-71

[16] Jens Minnerup, Ilka Kleffner, Heike Wersching, : Postpartum Eclampsia: It is Really Never Too Late-A Case of Eclampsia 8 Weeks after Delivery. Stroke Research and Treatment 2010 (2010), Article ID 798616, http://dx.doi.org/10.4061/2010/798616 